\title{
Vibration Therapy and Its Influence on Health
}

\author{
Ivan Uher ${ }^{1 *}$, Alicja Pasterczyk ${ }^{2}$, Monika Bigosińska ${ }^{3}$ and Milena Švedová ${ }^{4}$ \\ ${ }^{1}$ Institute of Physical Education and Sport, PJ Šafárika University, Kosice, Slovakia \\ ${ }^{2}$ Vitberg Jacek Sikora, Nowy Sacz, Poland \\ ${ }^{3}$ Department of Physical Education, Institute of Physical Education, State University of Applied Sciences, Nowy Sacz, Poland
}

${ }^{4}$ Faculty of Management, Prešov University in Prešov, Slovakia

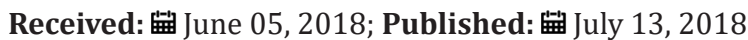

*Corresponding author: Ivan Uher, Institute of Physical Education and Sport, Pavla Jozefa Šafárika University, Slovakia

\begin{abstract}
The history of the development of vibrotherapy (VT) dates back to the half of the nineteenth century, when French neurologist Jean-Martin Charcot designed vibration chair for treatment of Parkinson disease. Since then VT got as far as the world's first medical device "Vitberg+" that was introduce by Vitberg company in 2016. Vibrotherapy has recently gain popularity, many studies have provided insight into the benefits of using vibration for enhancement of overall health. The aim of our paper is to review current literature on VT, help readers to better understand the effects of vibration on human body. We can add that valid evidence suggests that vibration is effective in enhancing various medical conditions, although the exact mechanisms mediating these effects are still not well understood. In that context, further research is needed for verification and clarification of the impact of vibration, vibrotherapy on the human health.
\end{abstract}

Keywords: Vibration; Quality of Life; Human health; Lifestyle; Mental Health

\section{Introduction}

Vibration is a mechanical incitement characterized by an oscillatory wave. The biomechanical factors determining its intensity are amplitude, frequency and magnitude of the fluctuations. The amount of the oscillatory movement regulates the amplitude of the vibration, the replication rate of the cycles of fluctuation indicates the incidence of the vibration, and the acceleration specifies the magnitude of the vibration [1]. We recognize three types of VT. First, the vibration enters the human body via hand when gripping a vibrating dumbbell, barbell, or bar designed to stimulate upper body muscles, or via a pulley system. Second, the vibration is applied directly to the muscle locally to the sole of the foot for example or by vibrating cable. And the third, where the vibration enters via feet when standing on a vibration platform or in a lying position, so-called whole-body vibration (WBV). Actually, Vitberg company introduced first world medical device which applies whole body and local vibrotherapy simultaneously. We can pronounce that in the last decade the strategy for (e.g. chronic pain management, recovery after training or injury, amelioration of blood, lymph circulation and metabolism enhancement) has changed. Currently, as an alternative to analgesics and surgical treatment different methods of electrostimulation, laser and magnet therapy are used. Recent studies show that the future direction in above mentioned health issues will belong to the vibrotherapy.

\section{Physiological Benefits of Vibrotherapy}

Pain is the most common reason for physician consultation in most developed countries [2,3], with about nine out of ten adults experiencing it at some point in their life, and five out of ten working adults having it every year [4]. For instance, chronic low back pain (NSCLBP) has multifactorial origins and poses a diagnostic and therapeutic challenge. Americans and Europeans annually spend more than 50 billion to help alleviate lower back pain, and that number continue to grow [5]. Pharmacotherapy as a treatment for NSCLBP results in high cost, minimal pain reduction, side effects, and limited efficacy. In addition, pharmaceutical drug prescriptions such as opioid analgesics account for nearly $75 \%$ of all pharmaceutical overdose deaths [6]. Further, it has been proposed that the initial traumatic event causes a muscular hypertonia, which leads to inadequate circulation, which then enhances pain. In the long run, this can lead to immobilization, followed by muscular atrophy and pathophysiological loading patterns, which further establish pain chronification [7]. We understand that tissue healing is an intricate process that is regulated by circulation. Recent research supports that passive vibration can increase circulation and has plausible effect on chronic back pain [8-10]. Looking at the athletes and not only athletes many subjects develop excessive connective tissue fibrosis or poorly organized scar tissue in and around joints, muscles, tendons, ligaments, myofascial planes as a result of acute trauma, recurrent microtrauma, immobilization, or as a complication of surgical intervention. This can lead to chronic inflammation, soft tissue adhesions, tendinosis, fascial restrictions or dysfunction which in many cases responds poorly to conventional treatments [11]. In the given context, vibrotherapy shows its justification as a preventive and therapeutic tool.

In addition, many studies have provided insight into the benefit of using vibration training to enhance muscle strength. 
In fact, the improvement of muscular performance after a short period of vibration training has been quoted to be similar to what occurs after several weeks of heavy resistance training $[12,13]$. In one study vibration training is being utilized in, strength training, performance enhancement and rehabilitation. Despite the lack of research in this area, the literature that is currently available and the results of this case study imply that vibration therapy has the potential to aid in the management of acute soft tissue injury and the sequela of disuse and immobilization [13]. Although there is lack of strictly controlled studies on the vibration training effect, current findings in this area suggest that vibration may have a beneficiary acute and or chronic training effect on strength and power enhancement [14]. Now we know, that diseased arteries can't generate enough protective nitric oxid (NO). Sackner et al. [15] in his study claim that WBV accelerates releases significant amount of (NO) into the circulation of healthy subjects and patients with inflammatory diseases [15]. Furthermore, Herrero et al. [16] and the Japanese Society of Hypertension [17] asserts that passive vibration (PV) increases leg blood flow and neuromuscular activity. Also, Sakaguchi et al. [18] in his study demonstrated that a single session of whole body periodic acceleration (WBPA) treatment simultaneously improved coronary microcirculation and glucose tolerance in patients with type two diabetes (T2D) and what is more significant in patients who are incapable or unwilling to exercise at a sufficient level. We have evidence that urinary incontinence can be altered by exercise [19]. Farzinmehr et al. [20] claim that similar result can be achieve through vibrotherapy [20]. In addition, tissue repair consists of overlapping phases of inflammation, proliferation, and remodeling, where macrophages are present in all phases Pongkitwitonn et al. [21] suggest that low intensity vibration (LIV) increased cell number and the expression of healing- associated markers, while decreasing production of proinflammatory cytokines. Therefore, LIV may be beneficial for tissue repair by reducing inflammation and promoting a pro-healing macrophage phenotype in conditions such as diabetes. Taking together, accumulating evidence demonstrates that mechanical stimulation via low-intensity vibration enhance neuromuscular control, accelerate tissue regeneration has the potential to influence many cell types involved in tissue repair, macrophages are sensitive to mechanical signals. Even though underlying mechanism remains to be elucidated.

\section{Psychological Benefits of Vibrotherapy}

Depression is a major psychiatric condition in men worldwide [22]. Moreover, depression appears to be a major health problem among elderly. We have compelling evidence for the effectiveness of exercise in the treatment of youth and adult depression. However, due to the inherent symptoms of depression (lack of energy, low motivation to exercise), aerobic, anaerobic training could be too demanding especially in the first weeks of treatment. Wunram et al. [23] and his colleagues hypothesis that an easy to perform passive muscular training on WBV device has equal anti-depressive effects compared to a cardiovascular training. This study found strong support for the claim that WBV training add-on to exercise treatment in depressed adolescents, and can be applied in highly depressed adolescents, without drive to exercise, before more active physical activities can be administered. Koike et al. [24] examine whether vibroacoustic therapy (VAT) can improve the psychological symptoms of older cohorts, the authors found that VAT provided relaxation effect, and improved depression symptoms. Furthermore, body dissatisfaction is considered to be the most important component of disturbance since it refers to negative subjective evaluations of one's physical body (the majority of people reporting dissatisfaction with weight or body shape). As a result, when body image distress is very low, individual may not engage in healthy dieting and exercise - even if necessary to improve health outcomes. Rüütel and his colleagues [25] argue that Vibroacoustic therapy promotes changes in the state of mood and comfort, which are important for bodily well-being. Therefore, Vibroacoustic therapy can be used for reducing stress in a nonclinical population and can be added to the treatment programs, including interventions for diminishing body dissatisfaction. Attention deficit hyperactive disorder (ADHD) is associated with a reduced quality of life [26]. Children and adults with ADHD frequently experience problems in a social interaction, which can lead to social rejection, social isolation and discrimination $[27,28]$. Fuermaier et al. [29] asserts that WBV can improve cognitive performance of healthy individuals as well as of individuals with ADHD. The authors further claim that WBV treatment is relatively inexpensive and easy to apply and might therefore be of potential relevance of clinical use [29]. Presented findings might indicates that mechanic vibration, has the potential to improve cognition, reducing stress, play factor in self-esteem ultimately improve quality of life in any age group. However, more studies are needed to approximate, explain, complex issues of connection between vibrotherapy and mental health.

Nevertheless, when referring to vibration therapy it should by mentioned some of the leaders in this field. Particularly Vitberg Jacek Sikora company, that came on the market with innovative, advanced and original vibro-therapeutic product. This company is on the European market for over 20 years. The company is leading expert in the production of high quality vibro-therapeutic module. The product is Class IIa medical device, certified by the acknowledged body of TUV Rheinland (CE0197). For the past 11 years, the company have been operating vibrotherapy clinics (currently 52 of them across Poland), with approximately 1.5 thousand visits a day. We have to conclude, that until now no side effects was recorded in association with Vitberg products. In 2016 the company came out with the new generation "horizontal position module" - RAM Vitberg+. This product can be used for people who wants to shorten bodies regeneration process, people with various health concerns, simply anyone who wants to enjoy physical and mental equilibrium. Currently the company is exploring the technology and prototyping new version. The companies vision for the future embrace combing specific therapies (i.e. color, magnetic, music and vibration) into one which consequently will ameliorate, mediate, better outcome.

\section{Conclusion}

At the conclusion we can utter that vibrotherapy is a form of healing a prophylactic therapy that uses vibration as a stimulus. 
Vibration depending on its characteristic can affect the human body in specific way (e.g. change elasticity of blood vessels, improve blood flow to the peripheral circulation, enhance blood supply to the skin, stimulates lymphatic circulation, relieve pain, increase the elasticity of the tendons and fascia, increase muscle strength and flexibility, support metabolism, will improve mental health, relaxes whole organism etc.). Vibrotherapy can be used in different setting (e.g. fitness industry, medical centers, physical therapy, rehabilitation, professional sports, and beauty and wellness applications and so forth). Vibration can be used as a new form of exercise that is becoming more frequent employ to improve muscle strength, power and flexibility as well as coordination. Last but not list in the treatment of various mental health issues. At the very end, we can conclude, that the magnitude and broad spectrum of improvement provide a basis to embark expeditiously on such investigation [30]. In that respect more, research, evidence is needed to clarify mechanism behind, which at the present moment is far from being conclusive.

\section{References}

1. Bosco C (1985) Adaptive responses of human skeletal muscle to simulated hypergravity condition. Acta Physiol Scand 124(4): 507-513.

2. Debono DJ, LJ Hoeksema, RD Hobbs (2013) Caring for Patients with Chronic Pain: Pearls and Pitfalls. 2013 Journal of the American Osteopathic Association 113 (8): 620-627.

3. Turk DC, RH Dworki (2004) What should be the core outcome in chronic pain clinical trials? Art Res Therapy 6(4): 151-154.

4. Atul T, AA Ogle (2000) Diagnosis and Management of Acute Low Back Pain. Am Fam Physicia. 2000 61(6): 1779-1786.

5. (2014) Low Back Pain Fact Sheet. NIH National Institute of Neurological Disorders and Stroke. National Institutes of Health, Bethesda, MD, USA pp. $5115-5161$.

6. (2015) Centers for Disease Control and Prevention Policy impact: prescription painkiller overdoses.

7. Rittweger J, Just K, Kautzsch K, Reeg P, Felsenberg D (2002) Treatment of chronic lower back pain with lumbar extension and whole-body vibration exercise: a randomized controlled trial. Spine 27(17): 18291834.

8. Maddalozzo GF, B Kuo, A Walker, CD Maddalozzo, W Galver (2016) Comparison of 2 Multimodal Interventions With and Without Whole Body Vibration Therapy Plus Traction on Pain and Disability in Patiens With Nonspecific Chronic Low Back Pain. J Chiropr M 15(4): 243-251.

9. Boucher JA, J Abboud, F Nougarou, MC Normand, M Descarreaux (2015) The Effects of Vibration and Muscle Fatique on Trunk Sensomotor Control in Low Back Pain Patients. PLoS ONE 10(8): e0135838.

10. Lohman EB, KS Sackiriyas, GS Bains, G Calandra, C Lobo, et al. (2012) A comparison of whole body vibration and moist heat on lower extremity skin temperature and skin blood flow in healthy older individuals. Med Sci Monit 18(7): CR415-424.

11. Melham TJ, Sevier TL, Malnofski MJ, Wilson JK, Helfst RH (1998) Chronic ankle pain and fibrosis successfully treated with a new noninvasive augmented soft tissue mobilization technique (ASTM): a case report. Medicine and Science in Sports and Exercise 30(6): 801-804.

12. Bosco C, M Cardinale, O Tsarpela, E Lacatelli (1984) New trends in training science: the use of vibrations for enhancing performance. European Journal of Applied Physiology 53: 275-284.
13. Timmerman L, R James Andrews (1994) Arthroscopic treatment of posttraumatic elbow pain and stiffness. Am J Sports Med 22(2): 230235.

14. Luo J, B McNamara, K Moran (2005) The use of vibration training to enhance muscle strength and power. Sports med 35(1): 23-41.

15. Sackner MA, E Gummels, JA Adams (2015) Nitric Oxide is Released into Circulation with Whole-Body, Periodic Accelaration. CHEST 2005 127(1): 30-39.

16. Herrero AJ, H Menendez, L Gil, J Martin, TMartin, et al. (2011) Marin Effects of whole-body vibration on blood flow and neuromuscular activity in spinal cord injury. Spinal Cord 49(4): 554-559.

17. (2012) The Japanese Society of Hypertesion. Passive vibration on the legs reduces peripheral and systemic arterial stiffness. Hypertension Research 35: 126-127.

18. Sakaguchi M, S Fukuda, K Shimada, Y Izumi et al. (2012) Preliminary observations of passive exercise using whole body periodic acceleration on coronary microcirculation and glucose tolerance in patients with type 2 diabetes. Japanese College of Cardiology 60(4): 283-287.

19. Hagovska M, J Švihra, A Buková, A Horbacz, D Dračková, et al. (2017) Prevalence of urinary incontinence in females performing high-impact exercises. International Journal of Sports Medicine 38(3): 210-216.

20. Farzinmehr A, A Moezy, J Koohpayehzadeh, M Kashanian (2015) A comparative Sudy of Whole Body Vibration Training and Pelvic Floor Muscle Training on Women's Stress Urinary Incontinence: Three-month Follow-up. J of Family and Reproductive health 9(4): 147-154.

21. Pongkitwitoon S, EM Weinheimer-Haus, TJ Koh, S Judex (2016) Lowintensity vibrations accelerate proliferation and alter macrophage phenotype in vitro. J of Biomechanics 49(5): 793-796.

22. Bettge S, N Wille, C Barkmann, M Schulte-Markwort, U Ravens- Sieberer (2008) Depressive symptoms of children and adoles- cents in a German representative sample: results of the BELLA study. Eur Child Adolesc Psychiatry 17(Suppl 1): 71-81.

23. Wunram HL, S Hamacher, M Hellmich, M Volk, F Jänicke et al. (2017) Whole body vibration added to treatment as usual is effective in adolescents with depression: a partly randomized, tree-armed clinical in inpatients. Eru Child Adolesc Psych 27(5): 645-662.

24. Koike Y, M Hoshitani, Y Tabata, K Seki, R Nishimura, Y Kano (2012) Effects of Vibroacoustic Therapy on Elderly Nursing Home Residents with Depression. J Phys Ther Sci 24(3): 291-294.

25. Rüütel E (2004) Sociocultural context of body dissatisfaction and possibilities of vibroacoustic therapy in diminishing body dissatisfaction. Pub. Trü Kiriastus. Tallinn Pedagogical University. Dissertation paper.

26. Agarwal R, M Goldenberg, R Perry, WW IsHak (2012) The quality of life of adults with attention deficit hyperactivity disorder: A systematic review. Innovations in clinical neuroscience 9(5-6): 10-21.

27. Mueller AK, ABM Fuermaier, J Koerts, L Tucha (2012) Stigma in attention deficit hyperactivity disorder. ADHD Attention Deficit and Hyperactivity Disorders 4(3): 101-114.

28. Lange KW, S Reichl, KM Lange, L Tucha, O Tucha (2010) The history of attention deficit hyperactivity disorder. ADHD Attention Deficit and Hyperac- tivity Disorders 2(4): 241-255.

29. Fuermaier ABM, LTucha, J Koerts, MJG van Heuvelen, EA van der Zee, et al. (2014) Good Vibrations - Effects of Whole Body Vibration on Attention in Healthy Individuals and Individuals with ADHD. PLoS ONE 9(2): e90747.

30. Cimboláková I, S Farkašová, Iannaccone O, Rácz M, Dulínová F, et al. (2015) Výskum v medicíne a etika. Košice: Equilibria pp. 65. 
ISSN: 2574-1241

DOI: 10.26717/BJSTR.2018.06.001406

Ivan Uher. Biomed J Sci \& Tech Res

(C) (i) This work is licensed under Creative

Submission Link: https://biomedres.us/submit-manuscript.php

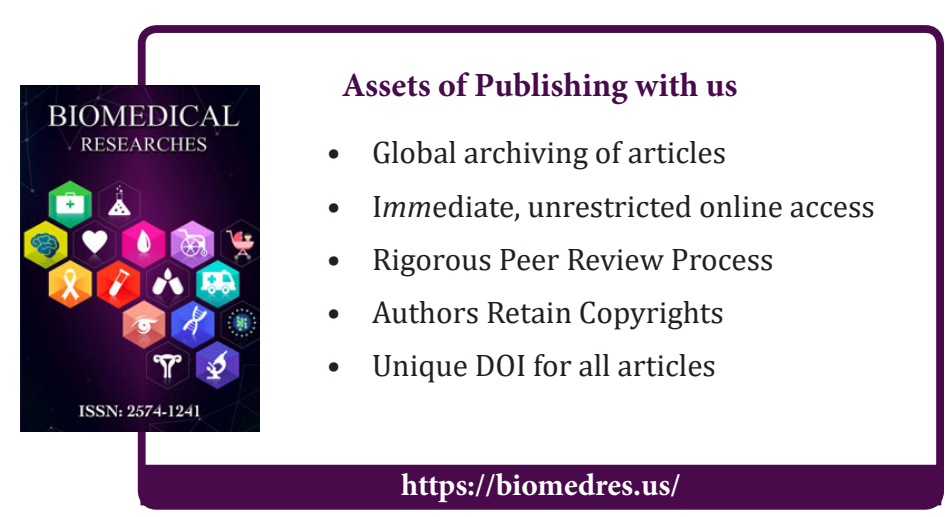

